\title{
Does Ordinary Portland Cement contain amorphous phase? A quantitative study using an external standard method
}

\author{
D. Jansen, ${ }^{\text {a) }}$ Ch. Stabler, F. Goetz-Neunhoeffer, S. Dittrich, and J. Neubauer \\ GeoZentrum Nordbayern, Mineralogy, University Erlangen-Nuremberg, Erlangen 91054, Germany
}

(Received 17 November 2010; accepted 1 January 2011)

\begin{abstract}
A suitable external standard method which was first described by O'Connor and Raven (1988) ("Application of the Rietveld refinement procedure in assaying powdered mixtures," Powder Diffr. 3, 2-6) was used to determine the quantitative phase composition of a commonly used Ordinary Portland Cement (OPC). The method was also applied in order to determine amorphous contents in OPC. Also investigated were the impact of atomic displacement parameters and the microstrain on the calculated amorphous content. The investigations yielded evidence that said parameters do indeed exert an influence on the calculated amorphous content. On the basis of the data produced we can conclude that the method used is entirely to be recommended for the examination of OPC. No significant amorphous content could be proven in the OPC used. (C) 2011 International Centre for Diffraction Data. [DOI: 10.1154/1.3549186]
\end{abstract}

Key words: Ordinary Portland Cement, amorphous content, external standard, $G$ factor

\section{INTRODUCTION}

The worldwide consumption of Ordinary Portland Cement (OPC), the most commonly used foundation for building materials on this planet, amounts to around 25 $\times 10^{6}$ tons a year. OPCs are complex powders of worldwide importance, and knowledge of their mineralogical compositions is of great economic importance inasmuch as it enables us to predict hydration behavior. Major phases are alite, belite, aluminate, and ferrite. Lime, periclase, as well as alkali sulfates may also exist as minor phases in cement clinkers (Taylor, 1997). Furthermore, sulfate carriers are added to the clinker to avoid an unintended rapid setting of the cement. As a result, OPCs are mixtures of ten and more phases. This means that the quantitative analysis of OPCs is quite a challenging task.

The cement industry uses a number of techniques to characterize their clinkers and final cement products, such as the Bogue method, microscopic point counting, and quantitative X-ray diffraction. Quantitative phase analysis of OPCs and clinkers based on single-peak intensities has only a limited applicability to OPCs because of overlapping reflections and the tendency to preferred orientations displayed by several phases. These limitations of single-peak intensity methods can be overcome by utilizing the Rietveld method of refinement (Rietveld, 1969).

Rietveld analysis always gives the total of the determined crystalline phases normalized to $100 \mathrm{wt} \%$ (Hill and Howard, 1987) [Eq. (1)]. If amorphous or unknown phases are present, the amounts of the crystalline phases estimated by the analysis will differ from the actual amounts present. Here,

\footnotetext{
a) Author to whom correspondence should be addressed. Electronic mail: djan@geol.uni-erlangen.de
}

$$
c_{j}=\frac{S_{j}(Z M V)_{j}}{\sum_{i=1}^{n} S_{i}(Z M V)_{i}},
$$

where $c_{j}=$ weight fraction of phase $j, S_{j}=$ Rietveld scale factor of phase $j, Z=$ number of f.u. per unit cell, $M=$ mass of the f.u., and $V=$ unit-cell volume.

Nevertheless, the presence of a glassy or amorphous component in cements and clinkers has been debated by several authors (Maki, 1979; Han et al., 1980). X-ray experiments have been performed in order to determine amorphous contents in cements and clinkers. Mainly two strategies, namely, internal standard methods as well as external standard methods, have been reported.

De La Torre et al. (2001) examined several standard materials using the internal standard method and concluded that corundum is the best standard, displaying as it does contain almost no amorphous content. De La Torre et al. (2001) assumed, in addition, that atomic displacement parameters exerted an impact on the quantitative results. Furthermore, it was shown that the phase alite has an amorphous content of $21.7 \mathrm{wt} \%$. The impact of the atomic displacement parameters on the scale factors was also described by Madsen et al. (2001), who assumed that errors made when using incorrect values for the atomic displacement parameters are propagated to the quantitative analysis. Le Saoût et al. (2007) examined cementitious materials by the use of external and internal methods. They employed the external standard method in order to avoid problems of homogenization. With regard to the internal standard method, they expressed doubts as to whether levels of amorphous phases below $10 \mathrm{wt} \%$ can be proven. Le Saoût et al. (2007) also noted that it is imperative to take into consideration the influence of refinement parameters on the quantification of amorphous contents. More research concerning the amorphous level of cements and clinkers was carried out by Whitfield and Mitchell (2003). They employed the internal standard method and calculated an amorphous content in the cement used of 18 to $25 \mathrm{wt} \%$. They concluded that the most serious source of error is the standard used and its amorphous content. Mathematical consequences of the experimental approach for in- 
ternal standard methods have been worked out by Westphal et al. (2009). They showed that the calculation of the amorphous content via Rietveld analysis using an internal standard follows a nonlinear function, which in turn leads to a significant degree of error especially when determining minor amounts of amorphous content. Thus, Westphal et al. (2009) concluded that to prove amorphous contents below $20 \mathrm{wt} \%$ using an internal standard is quite a challenging task because of the considerable degree of error which is also a function of the amount of standard added. For low amounts of amorphous content in the sample (like OPCs) Westphal et al. (2009) recommended an amount of internal standard measuring at least $50 \mathrm{wt} \%$. Even with that amount of internal standard there exists an uncertainty of the amorphous portion of almost $4 \mathrm{wt} \%$, as compared to the assumed uncertainty of $1 \mathrm{wt} \%$ of the Rietveld quantification.

It is certainly the case that determination of amorphous contents from analyses using internal standards is a very challenging operation indeed. First of all, a proper mixing of the standard with the sample has to be guaranteed. Furthermore, the experiments are complicated enormously by issues such as microabsorption especially if significant differences exist between the respective mass attenuation coefficients (MACs) of sample on one hand and standard on the other (Hermann and Ermrich, 1989).

Suherman et al. (2002) employed internal and external standard methods in order to examine the amorphous content of different cement clinkers and described an amorphous content in clinkers amounting to between 6.1 and 15.9 wt \%, depending on clinker type and on the method (internal or external standard) used. They refer to O'Connor and Raven (1988) who recommended an external standard method using a $G$ factor for examinations of powdered mixtures as an alternative to conventional discrete peak methods as described by Klug and Alexander (1974) and Chung (1974). O'Connor pointed out that it is imperative to be aware of the degree of crystallinity of the standard used, which ideally should be $100 \mathrm{wt} \%$. The calculation of a $G$ factor as a calibration factor for the whole experimental setup has not subsequently been used for powder diffraction experiments on hydrating cementitious systems.

\section{EXPERIMENTAL}

In the experiments we performed we made use of an Ordinary Portland Cement CEMI 52.5R. As only small amounts of sample are necessary for the XRD experiments performed, representative components for analysis were obtained by using the "cone and quarter" method. All samples were ground to a grain size of about $10 \mu \mathrm{m}$ using a McCrone micronizing mill (liquid: water free ethanol). Standard zircon was recrystallized from Alfa Aesar zircon. To this end the zircon was heated at $1300{ }^{\circ} \mathrm{C}$ for $4 \mathrm{~h}$. Afterwards the zircon was cooled in $5 \mathrm{~h}$ to $150{ }^{\circ} \mathrm{C}$. A second thermal treatment was carried out at $1400{ }^{\circ} \mathrm{C}$ for $6 \mathrm{~h}$ and the zircon was cooled again. The treated zircon was found to be a suitable standard with a crystallinity as good as the corundum standard recommended by De La Torre et al. (2001).

$\mathrm{X}$-ray powder diffraction patterns were recorded on a D8 automated diffractometer equipped with a LynxEye positionsensitive detector. Cement and standard were measured as
TABLE I. Data acquisition conditions for the X-ray experiments performed.

\begin{tabular}{cc}
\hline \hline Instrument & Bruker D8 \\
Radiation & $\mathrm{Cu} K \alpha$ \\
Geometry & Bragg-Brentano \\
Divergence slit & $0.3^{\circ}$ \\
Generator & $40 \mathrm{~mA}, 40 \mathrm{kV}$ \\
Range & $7^{\circ}$ to $70^{\circ}$ \\
Step width & $0.02^{\circ}$ \\
Integration time/step & $1 \mathrm{~s}$ \\
Detector & LynxEye (PS detector) \\
\hline \hline
\end{tabular}

front loaded pressed-powder samples, seven times, respectively, using the same conditions and settings as shown in Table I.

To ensure a proper detection of all phases in the OPC used, minor-phase enrichment experiments were performed. The dissolution of the interstitial phases using $\mathrm{KOH}$ sucrose solution permits an accurate analysis of the silicate phases such as alite and belite (Gutteridge, 1979). The dissolution of the silicate phases using a salicylic acid-methanol solution permits an accurate analysis of the interstitial phases (Struble, 1985).

Phase composition of the OPC used was determined using the peak finding program EVA 14 from Bruker AXS. TOPAS Version 4.2 from Bruker AXS was used as a leastsquares Rietveld refinement program (fundamental parameter approach). The scale factors for each phase were calculated using TOPAS. Table II shows the models used for the Rietveld refinement of each of the phases detected in the OPC, as well as the respective ICSD codes.

To avoid complications that might possibly have ensued from mixing an internal standard with the cement used, we

TABLE II. Structure models used for the Rietveld refinement of the OPC.

\begin{tabular}{crcc}
\hline \hline Phase & ICSD code & Occurrence & MAC $\left(\mathrm{cm}^{2} / \mathrm{g}\right)$ \\
\hline Zircon & $158108^{\mathrm{a}}$ & Standard & 82.9 \\
Zircon & $71943^{\mathrm{b}}$ & Standard & 82.9 \\
Zircon & $15759^{\mathrm{c}}$ & Standard & 82.9 \\
Alite & $94742^{\mathrm{d}}$ & Cement & 101.4 \\
Belite & $963^{\mathrm{e}}$ & Cement & 93.8 \\
$\alpha^{\prime}-\mathrm{C}_{2} \mathrm{~S}$ & $\mathrm{f}$ & Cement & 93.8 \\
$\mathrm{C}_{3} \mathrm{~A}_{\text {kub }}$ & $1841^{\mathrm{g}}$ & Cement & 86.9 \\
$\mathrm{C}_{3} \mathrm{~A}_{\text {ortho }}$ & $100220^{\mathrm{h}}$ & Cement & 86.9 \\
$\mathrm{C}_{4} \mathrm{AF}$ & $51265^{\mathrm{i}}$ & Cement & 134.8 \\
Gypsum & $27221^{\mathrm{j}}$ & Cement & 63.3 \\
Bassanite & $380286^{\mathrm{k}}$ & Cement & 73.4 \\
Anhydrite & $16382^{\mathrm{l}}$ & Cement & 77.4 \\
Calcite & $80869^{\mathrm{m}}$ & Cement & 74.1 \\
Quartz & $174^{\mathrm{n}}$ & Cement & 36.0 \\
Arcanite & $79777^{\mathrm{o}}$ & Cement & 86.5 \\
Silicon & $51688^{\mathrm{p}}$ & Standard & 63.7 \\
\hline \hline
\end{tabular}

${ }^{\mathrm{a}}$ Kolesov et al., 2001.

${ }^{\mathrm{b}}$ Mursic et al., 1992.

${ }^{\mathrm{c}}$ Robinson et al., 1971.

${ }^{\mathrm{d}}$ De La Torre et al., 2002.

' $\mathrm{J}$ ost et al., 1977.

${ }^{\mathrm{f}}$ Mueller, 2001.

${ }^{\mathrm{g}}$ Mondal and Jeffery, 1975.

${ }^{\mathrm{h}}$ Takéuchi and Nishi, 1980.
${ }^{\mathrm{i} J u p e}$ et al., 2001.

${ }^{\mathrm{j}}$ Pedersen, 1982.

${ }^{\mathrm{k}}$ Weiss and Bräu, 2009.

${ }^{\mathrm{I}}$ Kirfel and Will, 1980.

${ }^{\mathrm{m}}$ Maslen et al., 1995.

${ }^{\mathrm{n}}$ Le Page and Donnay, 1976.

${ }^{\circ}$ Ojima et al., 1995.

${ }^{\mathrm{p}}$ Többens et al., 2001. 
TABLE III. Examined zircon/NIST 622 mixtures.

\begin{tabular}{cccc}
\hline \hline Mixture & Zircon (wt \%) & NIST $622($ wt \%) & MAC $\left(\mathrm{cm}^{2} / \mathrm{g}\right)$ \\
\hline 1 & 25 & 75 & 54.35 \\
2 & 50 & 50 & 63.89 \\
3 & 75 & 25 & 73.44 \\
\hline
\end{tabular}

decided to make use of an external standard method. The well-known zircon standard used in the study was employed for the derivation of factor $G$ using Eq. (2) (O'Connor and Raven, 1988),

$$
G=s_{\mathrm{zir}} \frac{\rho_{\mathrm{zir}} V_{\mathrm{zir}}^{2} \mu_{\mathrm{zir}}^{*}}{c_{\mathrm{zir}}},
$$

where $s_{\text {zir }}=$ Rietveld scale factor of zircon, $\rho_{\text {zir }}=$ density of zircon, $V_{\text {zir }}=$ unit-cell volume of zircon, $C_{\text {zir }}=$ weight fraction of zircon $\left(100\right.$ wt $\%$ ), and $\mu_{\text {zir }}^{*}=$ MAC of zircon.

The calculated factor $G$ represents a calibration factor for the whole experimental setup and comprises the diffractometer used, radiation, and all data acquisition conditions, such as temperature and integration time. This factor $G$ was then used to determine the mass concentration of each phase $j$ in the sample [Eq. (3)]. This meant that the sample had to be measured under the same conditions as the standard. Here,

$$
c_{j}=s_{j} \frac{\rho_{j} V_{j}^{2} \mu_{\text {sample }}^{*}}{G} .
$$

In multiphase systems the absorption of X-rays strongly depends on the linear attenuation coefficients and the mean particle size of the single phases. If the linear attenuation coefficients differ strongly from each other, effects of microabsorption can occur if a critical particle size defined by Brindley (1945) is exceeded, leading to an underestimation of phases with a high linear attenuation coefficient (De La Torre and Aranda, 2003). The linear attenuation coefficients of the phases of an OPC (except the ferrite phase) do not differ strongly from each other. The ferrite-phase yielding the highest attenuation coefficient only appears as interstitial phase in the multiphase cement grains of technically produced OPCs. Therefore, only small particle sizes (around $1 \mu \mathrm{m})$ of this phase can be expected leading to negligible

TABLE IV. Chemical composition and mass attenuation coefficient of the OPC used.

\begin{tabular}{ccc}
\hline \hline Oxide & wt $\%$ & $\mathrm{MAC}\left(\mathrm{cm}^{2} / \mathrm{g}\right)$ \\
\hline $\mathrm{CaO}$ & 66.7 & $124.04 \times 0.667=82.73$ \\
$\mathrm{SiO}_{2}$ & 22.9 & $36.03 \times 0.229=8.25$ \\
$\mathrm{Al}_{2} \mathrm{O}_{3}$ & 3.8 & $31.69 \times 0.038=1.2$ \\
$\mathrm{Fe}_{2} \mathrm{O}_{3}$ & 1.3 & $214.9 \times 0.013=2.79$ \\
$\mathrm{MgO}$ & 0.8 & $28.6 \times 0.008=0.229$ \\
$\mathrm{Na} 2$ & 0.1 & $24.97 \times 0.001=0.025$ \\
$\mathrm{~K}_{2} \mathrm{O}$ & 0.7 & $122.3 \times 0.007=0.856$ \\
$\mathrm{SO}_{3}$ & 3.4 & $44.46 \times 0.034=1.51$ \\
$\mathrm{TiO}_{2}$ & 0.2 & $124.6 \times 0.002=0.249$ \\
$\mathrm{P}_{2} \mathrm{O}_{5}$ & 0.1 & $39.66 \times 0.001=0.04$ \\
$\mathrm{OPC}$ & & 97.9 \\
\hline \hline
\end{tabular}

microabsorption effects (Le Saoût et al., 2011).

In order to evaluate the accuracy of the method presented we applied the method to powder mixtures of known composition. For this purpose we produced mixtures of the zircon-standard material and a NIST glass (NIST 622) of defined ratios. The mass attenuation coefficient of the NIST glass is $44.8 \mathrm{~cm}^{2} / \mathrm{g}$. The mass attenuation coefficients of the mixtures are shown in Table III. In order to guarantee a proper mixing both components were ground and sieved to a particle size below $5 \mu \mathrm{m}$ and were then homogenized over 2 weeks. The amount of zircon in the mixtures was calculated using the $G$ factor derived from the pure zircon standard and the calculated scale factors for zircon from Rietveld refinement of the mixtures.

For all cement phases the values $\rho$ and $V$ were computed within the refinement, both of them being checked against data from the literature (Table II). Scale factors for the phases detected in the OPC were acquired from the Rietveld refinement. The mass attenuation coefficient of the OPC $\left(\mu_{\text {OPC }}^{*}\right)$ was measured and calculated from elemental analysis carried out by X-ray fluorescence spectrometry. The mass attenuation coefficient of the OPC used was found to be $97.9 \mathrm{~cm}^{2} / \mathrm{g}$. The chemical composition of the OPC and the mass attenuation coefficients of the oxides used (International Union for Crystallography, 2004) are given in Table IV.

We furthermore made use of different models for the zircon standard used. Mursic et al. (1992), Kolesov et al. (2001), and Robinson et al. (1971) all suggested the same symmetry (I41/amdZ). They differ strongly, however, in their suggestions regarding the refined atomic displacement parameters. When using Rietveld programs, the user has always to ensure that correct values are being employed with regard to atomic displacement parameters. Most of the displacement parameters given in the literature are anisotropic displacement factors (e.g., $U_{\text {aniso }} / B_{\text {aniso }}$ ). When using the graphical user interface some Rietveld programs will not convert those anisotropic values into equivalent isotropic values. Therefore, in such cases the user needs to calculate the equivalent isotropic displacement factor himself. The calculation of the equivalent isotropic displacement factor is an eigenvalue calculation so that the equivalent isotropic parameter can be easily calculated from the anisotropic values given (Fischer and Tillmanns, 1988). Second, in the crystallographic literature, there tend to occur inconsistent terms and symbols for said parameters (Trueblood et al., 1996). $U\left(\AA^{2}\right)$ is the mean square displacement of an atom from its equilibrium position $x$.

The Debye-Waller factor $B$ can be derived from $U$ by multiplying the value for $U$ with $8 \pi^{2}$. Very often, atomic displacement parameters are given as $\beta$ 's. These parameters have then to be converted into equivalent $B$ 's for the Rietveld programs, employed while taking into account the reciprocal lattice vectors $a^{*}, b^{*}$, and $c^{*}$. If these parameters are not converted and inserted into the Rietveld software, then the software will sometimes automatically employ the default value 1 , which is in many cases far away from the correct values for ions in inorganic solid-state structures. In order to estimate the error that might possibly ensue from different and/or wrong atomic displacement parameters, we made use 


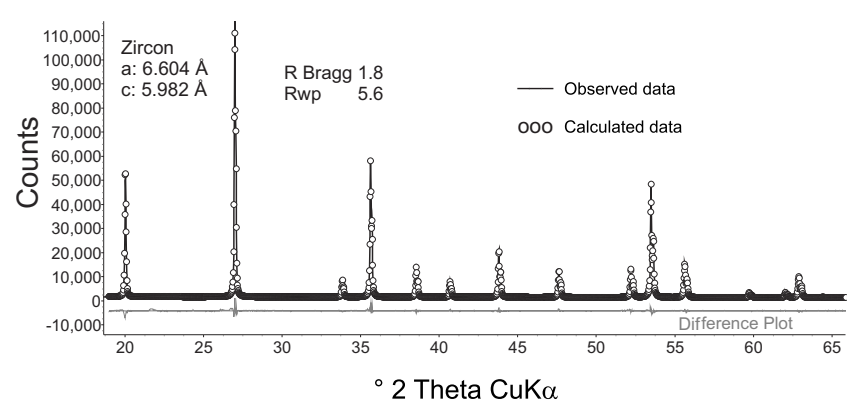

Figure 1. Rietveld refinement of a powder pattern of the zircon standard.

of all three zircon structures and added the value 1 at all sides of the zircon structure used by Robinson et al. (1971), knowing that the values are incorrect.

During Rietveld refinement the operator has the opportunity to refine the strain of all phases in the mixture. Real crystals contain imperfections which tend to produce local distortions of the lattice. This fact has an impact on peak profiles (Dinnebier and Billinge, 2008). The refinement of the strain leads to a better agreement between observed and calculated data. Although the refinement of the strain is important, it is not always to be recommended. Especially in a mixture of many phases such as cements, any refinement of the strain might lead to wrong strain values. The fact that many phases in OPCs, such as bassanite, arcanite, and $\mathrm{C}_{4} \mathrm{AF}$, display small crystallite sizes and are difficult to differentiate from the background also complicates the refinement of the strain. Hence, it is recommended that the strain be refined using the residues of the minor-phase enrichment experiments, keeping these latter fixed while refining the OPC. In order to estimate the error that might be caused by different and/or wrong values for the microstrain, our calculation of the amount of amorphous phase present in the cement that we were using was a calculation of the same specifically as a function of the microstrain (Lorentz function) of the major phase alite.

Because of the problems with standard materials just discussed, we also made use of a silicon standard. We ground, to only a very slight degree, a single piece of a silicon single crystal produced for wafer production. These single crystals are known to have a high chemical purity, which, in turn, is important if one is to proceed on the assumption of a precisely correct mass attenuation coefficient of the standard. Silicon is a highly symmetric material (cubic, $F d-3 m$ ) which is very well known and used very often as a peak position standard. Because of the brittleness of the material $1 \mathrm{~min}$ grinding in a micronizing mill entirely sufficed in order to achieve our purpose. For this reason, we assume that no amorphous content was produced during the grinding process.

TABLE V. Computed $G$ factor and structural details regarding the zirconstandard employed.

\begin{tabular}{cc}
\hline \hline Scale factor from Rietveld & 0.002980685 \\
Cell volume & $2.60 \times 10^{-22} \mathrm{~cm}^{3}$ \\
Density & $4.67 \mathrm{~g} / \mathrm{cm}^{3}$ \\
Mass attenuation coefficient & $82.98 \mathrm{~cm}^{2} / \mathrm{g}$ \\
$G$ factor & $7.80824 \times 10^{-44} \mathrm{~cm}^{5} / \mathrm{wt} \%$ \\
\hline \hline
\end{tabular}

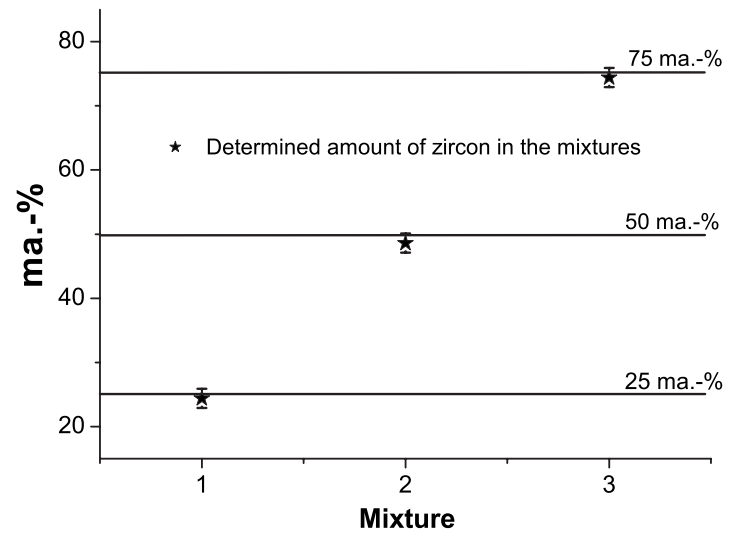

Figure 2. Comparison between the actual amount of zircon in the mixtures produced and the amount determined by the $G$-factor method.

\section{RESULTS AND DISCUSSION}

Figure 1 shows the Rietveld refinement of a recorded powder pattern of the zircon standard. A good fit was obtained as a result of Rietveld analysis. The calculated $G$ factor, as well as further structural details of the standard used, is shown in Table V. The calculated standard deviations (SDs) for the determined values for the $G$ factors were all approximately $1 \%$ of the mean values. For the calculation of the phase composition of the mixtures and the cement we made use of the mean values for the $G$ factors. Indeed, different values for the $G$ factors mean also an impact on the determined content of all crystalline phases and therefore different amorphous contents. Hence, it is to be recommended that the $G$ factor has to be calculated several times from samples of independent preparation.

Figure 2 shows the determined amounts of zircon in the mixtures of zircon and the NIST 622. The horizontal lines show the actual amounts present in the mixtures; the stars show the calculated amount using the $G$ factor derived from the pure zircon standard as well as the calculated standard deviations. It can be seen that there is close agreement between the actual amount of zircon in the mixtures and the amount calculated using the external $G$-factor standard method. Hence, we can conclude that the method is suitable for highly accurate examinations of phase compositions in mixtures with amorphous contents.

TABLE VI. Phases detected in the residues of the minor phase enrichment experiments (ICDD-PDF-Code).

\begin{tabular}{cc}
\hline \hline $\begin{array}{c}\text { Phases in the residue } \\
\text { using } \mathrm{KOH} \text { sucrose } \\
\text { solution }\end{array}$ & $\begin{array}{c}\text { Phases in the residue } \\
\text { using }\end{array}$ \\
$\begin{array}{c}\text { salicylic acid-methanol } \\
\text { solution }\end{array}$ \\
Alite (42-0551) & $\mathrm{C}_{3} \mathrm{~A}_{\text {kub }}(38-1429)$ \\
Belite $(33-0302)$ & $\mathrm{C}_{3} \mathrm{~A}_{\text {ortho }}(32-0150)$ \\
$\alpha^{\prime}-\mathrm{C}_{2} \mathrm{~S}^{\text {a }}$ & $\mathrm{C}_{4} \mathrm{AF}(30-0226)$ \\
Calcite $(05-0586)$ & Gypsum (33-0311) \\
Quartz $(46-1045)$ & Bassanite $(41-0224)$ \\
& Anhydrite (37-1496) \\
& Calcite (05-0586) \\
& Quartz (46-1045) \\
\hline
\end{tabular}

${ }^{\mathrm{a}}$ Mueller, 2001 . 
TABLE VII. Determination of concentrations of all phases in the OPC used.

\begin{tabular}{ccc}
\hline \hline Phase & wt \% & SD (wt \%) \\
\hline Alite & 56.8 & 1.2 \\
Belite & 13.1 & 0.6 \\
${\text { Alpha' }{ }_{2} \mathrm{~S}}_{\mathrm{C}_{3} \mathrm{~A}_{\text {kub }}}$ & 9.2 & 0.5 \\
$\mathrm{C}_{3} \mathrm{~A}_{\text {ortho }}$ & 4.4 & 0.3 \\
$\mathrm{C}_{4} \mathrm{AF}$ & 3.9 & 0.3 \\
Gypsum & 1.8 & 0.2 \\
Bassanite & 1.0 & 0.1 \\
Anhydrite & 1.2 & 0.1 \\
Calcite & 2.0 & 0.2 \\
Quartz & 2.0 & 0.2 \\
Arcanite & 0.4 & 0.1 \\
XX (total of crystalline phases) & $96.7 \pm 3.9$ & 0.1 \\
Amorphous + not determined+misfitted & $3.3 \pm 3.9$ & \\
\hline \hline
\end{tabular}

All phases detectable in the residues of the minor-phase enrichment experiments of the cement used are shown in Table VI. The calculated phase composition for the OPC used, including the amorphous content which was established (actual: amorphous + not determined + misfitted), is shown in Table VII (standard: zircon 158108). It was found that the OPC does not contain significant quantities of amorphous material. All in all, we were only able to observe an amorphous content of around $3.3 \mathrm{wt} \%$. In view of the large error of 3.9 wt \%, resulting from the additive effect of the errors of each single phase, we were not in the end able to prove the existence of any amorphous phase. The Rietveld refinement of the OPC is shown in Figure 3.

Except for some problems in the fit of the major phase alite, there is close agreement between the observed and the calculated data. Due to the fact that the fit for alite is not perfect-depending on superstructure and/or MI/MIII modifications-we assume that the misfit of the major phase alite is the cause of the amorphous content which was established, and which is, in this specific case, no glassy component but rather nonfitted parts of the crystalline phases. If we use the silicon as standard for the derivation of the $G$ factor, we even arrive at an amount of 98.8 wt $\%$ of crystalline phases, assuming the same error of 3.9 wt \% (Figure 4).

Since the silicon powder used was acquired from a single crystal, there is no reason to assume that it has a lower degree of crystallinity than commercial zircon powder. The Rietveld refinement of the silicon powder is shown in Figure 5.

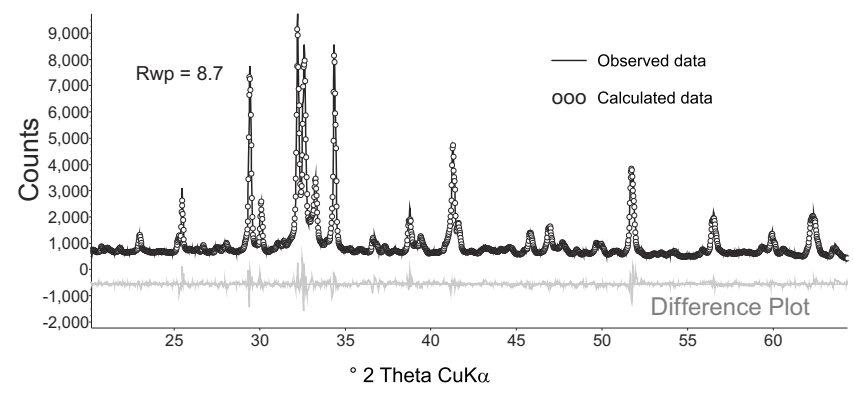

Figure 3. Rietveld refinement of a powder pattern of the OPC used.

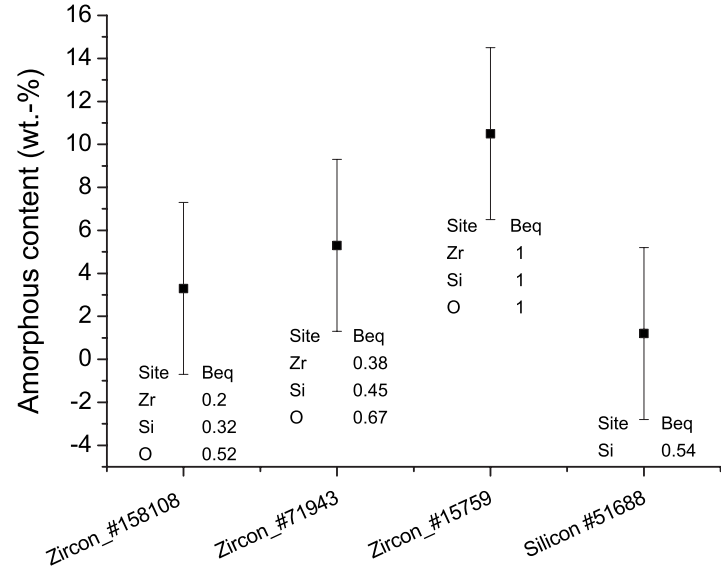

Figure 4. Amorphous content of the OPC used as a function of structures and atomic displacement parameters.

Furthermore, we calculated the $G$ factor using the zircon structures and the atomic displacement parameters reported by Mursic et al. (1992) and Robinson et al. (1971). These $G$ factors were then used to calculate over again the entire phase composition of the cement. Figure 4 shows the amorphous content of the cement as a function of the structures of the zircon employed. The higher the atomic displacement parameters in the structure of the standard are, the higher the calculated amount of the amorphous content of the investigated OPC. This fact might possibly be explained as follows.

The atomic displacement factors modify the atomic form factor $f$ and consequently also the structure factor $F$. Where the atomic displacement factors $U$ increase, the structure factor decreases correspondingly [Eq. (4)] (Dinnebier and Billinge, 2008),

$$
F \sim f \sim \mathrm{e}^{-U} .
$$

The structure factor $F$, in its turn, is proportional to the relative intensity $I$ resulting from the proposed structure [Eq. (5)] (Young, 1995),

$$
I \sim[F]^{2} .
$$

The scale factors $s$ obtained via Rietveld refinement convert the relative intensities resulting from the structures into the absolute intensities obtained from the experiment [Eq. (6)] (Hubbard et al., 1976),

$$
I_{\text {absolute }}=s \times I_{\text {relative }} .
$$

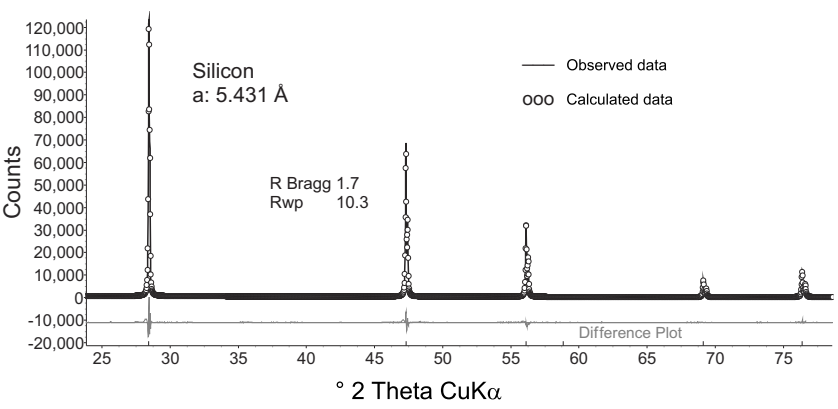

Figure 5. Rietveld refinement of a powder pattern of the silicon standard. 


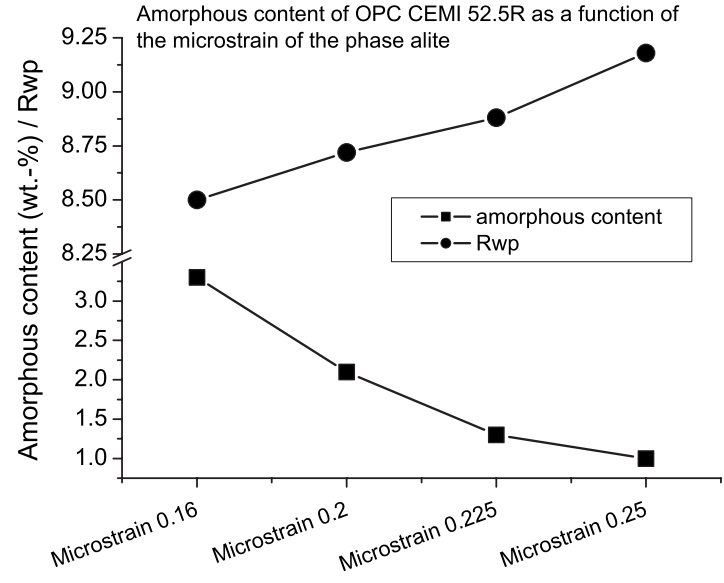

Figure 6. Amorphous content of the OPC used as a function of the microstrain for alite.

Where there is a low relative intensity due to large atomic displacement parameters, the Rietveld scale factor will tend to be high. This will, in turn, tend to give rise to a $G$ factor which is oversized and which will therefore result in an undersizedness of every single phase in the mixture [Eqs. (2) and (3)]. In this case, it is not to be recommended that one refers to an "amorphous content" with respect to the difference between the total of crystalline phases and 100 wt \% since it might be understood as a glassy (not crystalline) component.

Figure 6 shows the amorphous content of the OPC which we investigated as a function of the microstrain for the major phase alite, as well as the $R_{\mathrm{wp}}$ of the refinement.

It can be clearly seen that the microstrain had an impact on the amount of alite and therefore also on the amount of the amorphous phase established. Although the $R_{\mathrm{wp}}$ increases with increasing microstrain for the phase alite, no distinct worsening of the difference plot is visible until we reach a microstrain of about 0.225 (Figure 7).

The difference in the amount of amorphous content obtaining at a microstrain of 0.16 and that obtaining at a microstrain of 0.225 for the phase alite is already 2 wt $\%$. We assume that a very high value for the microstrain might give rise to this intensity, which is actually part of the background and thereby involved in the intensity (scale factor) of any phase.

Furthermore, any other sort of error made in computing the scale factors of the phases in the OPC (e.g., misfits of structures, imprecise lattice parameters, unrealistic crystallite sizes, insufficient characterization of the background below the peaks, etc.) or a failure to take into consideration any phase will likewise tend to create amorphous content. Therefore, we strongly recommend that care be taken to differentiate between amorphous (glassy, not crystalline) content and the amount of nondetermined phases arising through Rietveld refinement and amorphous content arising as a result of refinement misfits.

The results of the experiments which we performed lead to the conclusion that no amorphous content could be proven to exist in the OPC used. In light of the descriptions of possible experimental errors which we have given in this study, it is possible that certain findings regarding the discovery of amorphous content that have been published in recent years may, in fact, only have been the result of, e.g., inadequate atomic displacement parameters or other refined parameters. Especially atomic displacement parameters should only be used if they correspond to meaningful values which are between 0.005 and $0.02 \AA^{2}(U)$ for heavy atoms in inorganic solids and considerably higher in organic compounds $(0.02$ to $0.06 \AA^{2}$ ).

Indeed, an amorphous (glassy) content might be observed in other cements produced in any one of several other ways, such as white cements and calcium aluminate cements. The difference between the total of the detected crystalline phases and 100 wt $\%$ in our studies can be explained by misfits which occurred while performing Rietveld refinements of the complex OPC and which were therefore passed on to the computed scale factors. Finally, the study indicates that the method used is a very promising method for quantitative study of the phases in cements.

\section{CONCLUDING REMARKS}

The hydration of OPCs is a complex scientific issue and the kinetics of the hydration process is a topic which is still under discussion. Several scientists have published articles quantifying the crystalline phases of cement pastes during the process of hydration (Hesse et al., 2009; Scrivener et al., 2004). During hydration of OPCs, a C-S-H phase is formed which is hardly to be detected by X-ray diffraction because of its low degree of crystallinity. In order to arrive at the true phase content of each phase in the cement paste, the results obtained via Rietveld analyses have to be convertednamely, by taking into account also the C-S-H phase, the free water, and the bounded water (Hesse et al., 2009). The implementation of the method presented in this paper offers
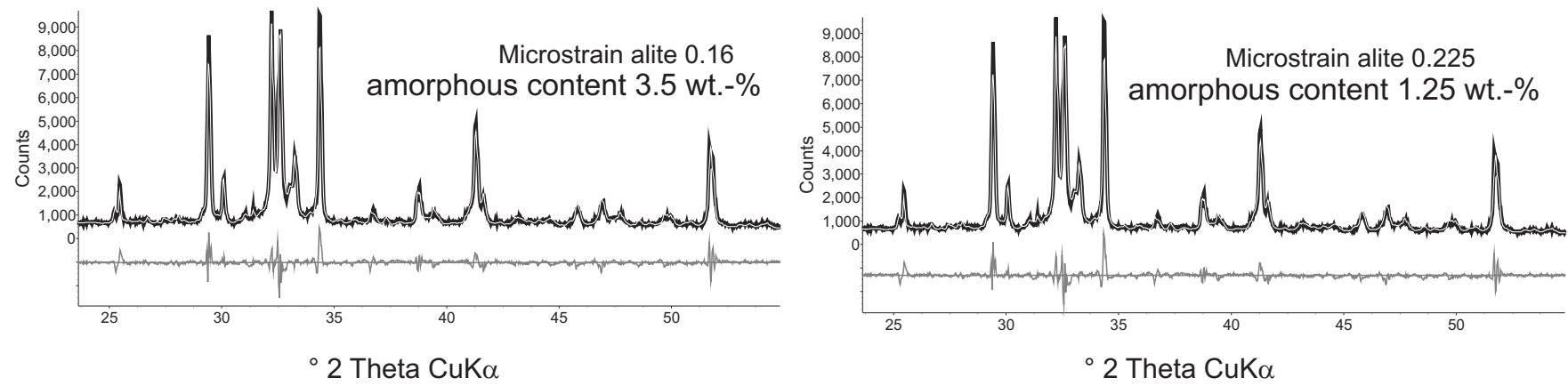

Figure 7. Rietveld refinement of a powder pattern of the OPC used using different microstrains for alite. 
a lot of advantages. First, the concentration obtaining in each phase can be detected directly from the scale factor. Second, errors in Rietveld quantification do not, here, necessarily have an impact on the other phases present in the OPC paste. Lastly, the difference between the total of crystalline phases and 100 wt $\%$ can be attributed directly to the amorphous components in the OPC paste, e.g., not to crystalline bounded water and to $\mathrm{C}-\mathrm{S}-\mathrm{H}$ phase. This makes it possible to calculate the amorphous content of the cement paste during hydration. The $G$-factor method which we have presented is very promising for the quantitative study of cement hydration.

\section{ACKNOWLEDGMENTS}

The authors would like to thank Rainer Hock and Helmuth Zimmermann of the Department of Crystallography and Structural Physics for useful discussion.

Brindley, G. W. (1945). "The effect of grain or particle size on x-ray reflections from mixed powders and alloys, considered in relation to the quantitative determination of crystalline substances by X-ray methods," Philos. Mag. 36, 347-369.

Chung, F. H. (1974). "Quantitative interpretation of X-ray diffraction patterns of mixtures. II. Adiabatic principle of X-ray diffraction analysis of mixtures," J. Appl. Crystallogr. 7, 526-531.

De La Torre, A. G. and Aranda, M. A. G. (2003). "Accuracy in Rietveld quantitative phase analysis of Portland cements," J. Appl. Crystallogr. 36, 1169-1176.

De La Torre, A. G., Bruque, S., and Aranda, M. A. G. (2001). "Rietveld quantitative amorphous content analysis," J. Appl. Crystallogr. 34, 196202.

De La Torre, A. G., Bruque, S., Campo, J., and Aranda, M. A. G. (2002). "The superstructure of $\mathrm{C}_{3} \mathrm{~S}$ from synchrotron and neutron powder diffraction and its role in quantitative phase analysis," Cem. Concr. Res. 32, 1347-1356.

Dinnebier, R. E. and Billinge, S. J. L. (2008). Powder Diffraction, Theory and Practice (The Royal Society of Chemistry, Cambridge).

Fischer, R. X. and Tillmanns, E. (1988). "The equivalent isotropic displacement factor," Acta Crystallogr., Sect. C: Cryst. Struct. Commun. 44, 775-776.

Gutteridge, W. A. (1979). "On the dissolution of the interstitial phases in Portland cement," Cem. Concr. Res. 9, 319-324.

Han, K. S., Glasser, F. P., and Gard, J. A. (1980). "Studies of the crystallization of the liquid phase in Portland clinker," Cem. Concr. Res. 10, 443-448.

Hermann, H. and Ermrich, M. (1989). "Microabsorption correction of X-ray intensities diffracted by multiphase powder specimens," Powder Diffr. 4, 189-195.

Hesse, Ch., Goetz-Neunhoeffer, F., Neubauer, J., Braeu, M., and Gaeberlein, P. (2009). "Quantitative in-situ X-ray diffraction analysis of early hydration of white cement," Powder Diffr. 24, 112-115.

Hill, R. J. and Howard, C. J. (1987). "Quantitative phase analysis from neutron powder diffraction data using the Rietveld method," J. Appl. Crystallogr. 20, 467-474.

Hubbard, C. R., Evans, E. H., and Smith, D. K. (1976). "The reference intensity ration $\mathrm{I} / \mathrm{Ic}$ for computer simulated powder patterns," J. Appl. Crystallogr. 9, 169-174.

International Union for Crystallography. (2004). International Tables for Crystallography, Volume C: Mathematical, Physical and Chemical Tables, 3rd ed., edited by E. Prince (Kluwer, Boston).

Jost, K. H., Ziemer, B., and Seydel, R. (1977). "Redetermination of the structure of $\beta$-dicalcium silicate," Acta Crystallogr., Sect. B: Struct. Crystallogr. Cryst. Chem. 33, 1696-1700.

Jupe, A. C., Cockcroft, J. K., Barnes, P., Colston, S. L., Sankar, G., and Hall, C. (2001). "The site occupancy of $\mathrm{Mg}$ in the brownmillerite structure and its effect on hydration properties: An X-ray/neutron diffraction and EXAFS study," J. Appl. Crystallogr. 34, 55-61.

Kirfel, A. and Will, G. (1980). "Charge density in anhydrite $\mathrm{CaSO}_{4}$, from $\mathrm{X}$-ray and neutron diffraction measurements," Acta Crystallogr., Sect. B:
Struct. Crystallogr. Cryst. Chem. 36, 2881-2890.

Klug, H. P. and Alexander, L. E. (1974). X-Ray Diffraction Procedures, 2nd ed. (Wiley, New York).

Kolesov, B. A., Geiger, C. A., and Armbruster, T. (2001). "The dynamic properties of zircon studied by single-crystal X-ray diffraction and Raman spectroscopy," Eur. J. Mineral. 13, 939-948.

Le Page, Y. and Donnay, G. (1976). "Refinement of the crystal structure of low-quartz," Acta Crystallogr., Sect. B: Struct. Crystallogr. Cryst. Chem. 32, 2456-2459.

Le Saoût, G., Füllmann, T., Kocaba, V., and Scrivener, K. L. (2007). "Quantitative study of cementitious materials by X-ray diffraction. Rietveld analysis using an external standard," Proceedings of the 12th ICCC, Montreal, Canada, 08-13 July 2007.

Le Saoût, G., Kocaba, V., and Scrivener, K. (2011). "Application of the Rietveld method to the analysis of anhydrous cement," Cem. Concr. Res. 41, 133-148.

Madsen, I. C., Scarlett, N. V. Y., Cranswick, L. M. D., and Lwin, T. (2001). "Outcomes of the International Union of Crystallography Commission on Powder Diffraction Round Robin on quantitative phase analysis: Samples 1a to 1h," J. Appl. Crystallogr. 34, 409-426.

Maki, I. (1979). "Mechanism of glass formation in Portland cement clinker," Cem. Concr. Res. 9, 757-763.

Man Suherman, P., van Riessen, A., O'Connor, B., Li, D., Bolton, D., and Fairhurst, H. (2002). "Determination of amorphous phase levels in Portland cement clinker," Powder Diffr. 17, 178-185.

Maslen, E. N., Streltsov, V. A., and Streltsova, N. R. (1995). "Electron density and optical anisotropy in rhombohedral carbonates. III. Synchroton X-ray studies of $\mathrm{CaCO}_{3}, \mathrm{MgCO}_{3}$ and $\mathrm{MgCO}_{3}$," Acta Crystallogr., Sect. B: Struct. Sci. 51, 929-939.

Mondal, P. and Jeffery, J. W. (1975). "The crystal structure of tricalcium aluminate, $\mathrm{Ca}_{3} \mathrm{Al}_{2} \mathrm{O}_{6}$," Acta Crystallogr., Sect. B: Struct. Crystallogr. Cryst. Chem. 31, 689-697.

Mueller, R. (2001). "Stabilisierung verschiedener dicalciumsilikatmodifikationen durch den einbau von phosphat: Synthese, Rietveldanalyse, kalorimetrie, " Diploma thesis, University of Erlangen.

Mursic, Z., Vogt, T., Boysen, H., and Frey, F. (1992). "Single-crystal neutron diffraction study of metamict zircon up to $2000 \mathrm{~K}$," J. Appl. Crystallogr. 25, 519-523.

O'Connor, B. H. and Raven, M. D. (1988). "Application of the Rietveld refinement procedure in assaying powdered mixtures," Powder Diffr. 3, $2-6$.

Ojima, K., Hishihata, Y., and Sawada, A. (1995). "Structure of potassium sulfate at temperatures from $296 \mathrm{~K}$ down to $15 \mathrm{~K}$," Acta Crystallogr., Sect. B: Struct. Sci. 51, 287-293.

Pedersen, B. F. (1982). "Neutron diffraction refinement of the structure of gypsum," Acta Crystallogr., Sect. B: Struct. Crystallogr. Cryst. Chem. 38, 1074-1077.

Rietveld, H. M. (1969). "A profile refinement method for nuclear and magnetic structures," J. Appl. Crystallogr. 2, 65-71.

Robinson, K., Gibbs, V., and Ribbe, P. H. (1971). "The structure of zircon: A comparison with garnet," Am. Mineral. 56, 782-791.

Scrivener, K. L., Füllmann, T., Gallucci, E., Walenta, G., and Bermejo, E. (2004). "Quantitative study of Portland cement hydration by X-ray diffraction/Rietveld analysis and independent methods," Cem. Concr. Res. 34, 1541-1547.

Struble, L. J. (1985). "The effect of water on maleic acid and salicylic acid extractions," Cem. Concr. Res. 15, 631-636.

Takéuchi, Y. and Nishi, F. (1980). "Crystal-chemical characterization of the $\mathrm{Al}_{2} \mathrm{O}_{3}-\mathrm{Na}_{2} \mathrm{O}$ solid-solution series," Z. Kristallogr. 152, 259-307.

Taylor, H. F. W. (1997). Cement Chemistry (Thomas Telford, London).

Többens, D. M., Stuesser, N., Knorr, K., Mayer, H. M., and Lampert, G. (2001). "The new high-resolution neutron powder diffractometer at the Berlin neutron scattering center," Mater. Sci. Forum 378-381, 288-293.

Trueblood, K. N., Bürgi, H.-B., Burzlaff, H., Dunitz, J. D., Gramaccioli, C. M., Schulz, H. H., Shmueli, U., and Abrahams, S. C. (1996). "Atomic displacement parameter nomenclature report of a subcommittee on atomic displacement parameter nomenclature," Acta Crystallogr., Sect. A: Found. Crystallogr. 52, 770-781.

Weiss, H. and Bräu, M. F. (2009). "How much water does calcined gypsum contain?," Angew. Chem., Int. Ed. 48, 3520-3524. 
Westphal, T., Füllmann, T., and Pöllmann, H. (2009). "Rietveld quantification of amorphous portions with an internal standard-mathematical consequences of the experimental approach," Powder Diffr. 24, 239-243. Whitfield, P. S. and Mitchell, L. D. (2003). "Quantitative Rietveld analysis of the amorphous content in cements and clinkers," J. Mater. Sci. 38, 4415-4421.

Young, R. A. (1995). The Rietveld Method (Oxford University Press, New York). 